\title{
Corrigendum to “On Providing Differentiated Service Exploiting Multi-Instance RPL for Industrial Low-Power and Lossy Networks"
}

\author{
Muhammad Mostafa Monowar $(\mathbb{D}$ and Mohammed Basheri \\ Department of Information Technology, Faculty of Computing and Information Technology, King AbdulAziz University, \\ Jeddah, Saudi Arabia \\ Correspondence should be addressed to Muhammad Mostafa Monowar; mmonowar@kau.edu.sa \\ Received 19 May 2020; Accepted 28 May 2020; Published 1 September 2020 \\ Copyright (c) 2020 Muhammad Mostafa Monowar and Mohammed Basheri. This is an open access article distributed under the \\ Creative Commons Attribution License, which permits unrestricted use, distribution, and reproduction in any medium, \\ provided the original work is properly cited.
}

In the article titled "On Providing Differentiated Service Exploiting Multi-Instance RPL for Industrial Low-Power and Lossy Networks" [1], the Acknowledgments section was omitted in error. The Acknowledgments section is shown below:

\section{Acknowledgments}

This work was supported by the Deanship of Scientific Research (DSR), King Abdulaziz University, Jeddah, under grant no. D-015-611-1439. The authors, therefore, gratefully acknowledge the DSR technical and financial support.

\section{References}

[1] M. M. Monowar and M. Basheri, "On Providing Differentiated Service Exploiting Multi-Instance RPL for Industrial LowPower and Lossy Networks," Wireless Communications and Mobile Computing, vol. 2020, Article ID 1748647, 12 pages, 2020. 